\title{
Jahrestagung 1987
}

Die Jahrestagung fand vom 7. bis 10 . Oktober 1987 statt - erstmals im schönen Passau.

In der Mitgliederversammlung gedachten die Anwesenden der seit der Münchener Tagung verstorbenen Kollegen Karl Wilhelm Geck, Curt Rühland, Hans Ulrich Evers und Wilhelm Wertenbruch. Die Vereinigung wird ihnen ein ehrendes Andenken bewahren. - Dem Alterspräsidenten der Vereinigung, Herrn Jahrreiß, der einen Ausstellungsband mit eigenen Bildern übersandt hatte, übermittelte die Vereinigung ihre Grüße.

Seit der letzten Jahrestagung sind 12 Kolleginnen und Kollegen neu in die Vereinigung aufgenommen worden. Die Vereinigung zählt nunmehr 346 Mitglieder.

Die nächste Jahrestagung wird vom 5. bis 8. Oktober in Tübingen stattfinden, die folgende voraussichtlich in Hannover.

Die Mitgliederversammlung wählte folgenden neuen Vorstand: Martin Heckel, Erhard Denninger, Christian Starck.

Die Vorträge und Diskussionen fanden in einem Hörsaal der Universität statt. Den Vorsitz führte Hans Zacher, die Diskussionen leiteten die Vorstandsmitglieder Christian Tomuschat und Martin Kriele.

Die Mitglieder der Vereinigung und ihre Begleiter erlebten am ersten Abend ein Orgelkonzert im Passauer Dom und waren anschlieBend Gäste des Universitätspräsidenten. Am zweiten Abend wurden sie durch den Präsidenten des bayerischen Landtags und dem Oberbürgermeister der Stadt Passau im Rathaus empfangen. Am dritten Abend unternahmen sie eine gesellige Dampferfahrt donauabwärts. Der traditionelle Sonnabendausflug führte zu den Innklöstern Vornbach (mit Orgelkonzert) und Reichersberg.

Dem in den Vorstand kooptierten Herbert Bethge kam an der Vorbereitung der Tagung und - gemeinsam mit den Ehefrauen der Passauer Kollegen - des Rahmen- und Begleitprogramms großes Verdienst zu. 
